Archives

16 | 1996

Pour une histoire comparée du vœu

\title{
Les théories du vœu dans le droit canon et la première scolastique
}

Charles de Miramon

\section{(2) OpenEdition}

Journals

Édition électronique

URL : http://journals.openedition.org/ccrh/2639

DOI : $10.4000 /$ ccrh.2639

ISSN : $1760-7906$

Éditeur

Centre de recherches historiques - EHESS

Édition imprimée

Date de publication : 16 avril 1996

ISSN : 0990-9141

Référence électronique

Charles de Miramon, « Les théories du vœu dans le droit canon et la première scolastique », Les

Cahiers du Centre de Recherches Historiques [En ligne], 16 | 1996, mis en ligne le 27 février 2009,

consulté le 10 décembre 2020. URL : http://journals.openedition.org/ccrh/2639 ; DOI : https://doi.org/ $10.4000 /$ ccrh.2639

Ce document a été généré automatiquement le 10 décembre 2020.

Article L.111-1 du Code de la propriété intellectuelle. 


\title{
Les théories du vœu dans le droit canon et la première scolastique
}

\author{
Charles de Miramon
}

1 L'histoire doctrinale du vœu au Moyen Âge est bien plus contrastée qu'une première approche pourrait le laisser penser. En effet, les médiévaux ne se contentent pas de s'intéresser aux trois vœux du religieux: la chasteté, l'obéissance et la pauvreté. Ils entendent le vœu non pas comme un simple marqueur de la profession monastique, mais plus généralement comme une parole à Dieu qui est aussi un acte. Ce concept ouvert se place dans la réflexion fournie à l'époque sur la parole comme acte et sur son efficacité1. La grammaire sémantique qui se développe fortement à partir du milieu du XIII ${ }^{e}$ siècle fournit les outils aux théologiens et aux juristes pour forger leurs typologies du vœu².

2 Nous nous intéressons ici à la période qui s'ouvre en 1140 pour s'arrêter vers le milieu du $\mathrm{XIII}^{\mathrm{e}}$ siècle. Pour le droit canon, cela correspond à un âge d'or qui part du Décret de Gratien (vers 1140), collection de textes canoniques qui compose le premier recueil général de droit pour l'Église et s'arrête à la Summa Aurea (entre 1250 et 1261) d'Henri de Suse dit Hostiensis. La période est partagée par l'apparition d'un deuxième code de droit canon qu'impose la papauté en 1234 : le Liber Extra. Durant la même période, la théologie se regroupe dans ce que l'on nomme la première scolastique depuis Abélard (1140) jusqu'à Guillaume d'Auxerre (1230).

3 Dans cette première ébauche, il ne sera traité des doctrines ni dans leur ensemble ni dans le détail. Il sera présenté quelques éclairages sur les concepts utilisés, les lieux de discussion et l'étendue de la casuistique. Enfin, à titre d'hypothèse, sera proposé un modèle de l'évolution de la doctrine de 1140 à $1250^{3}$.

\section{Les différents concepts utilisés ou forgés}

$4 \quad$ Il ne s'agit pas d'étudier ici les différentes constructions doctrinales, souvent variées, des différents penseurs de la période considérée mais de présenter les différentes typologies du vœu utilisées à l'époque. 


\section{Vœu simple / Vœu public}

Le vœu simple est celui que l'on prononce à haute voix ou dont on délibère mentalement avec précision et que l'on énonce devant aucun témoin ou peu de témoins. Ainsi, sur un esquif ballotté par la tempête, je peux faire vœu, si je m'en sors vivant, de me faire moine. Le vœu solennel est au contraire celui écrit dans une cédule ou prononcé devant de nombreux témoins ou, mieux encore, devant l'autorité religieuse lors ou après la liturgie. Un bon exemple de ce vœu solennel est celui de la prise de croix, rite par lequel le croisé fait vœu de partir à Jérusalem ${ }^{4}$. Cette division entre vœu simple et vœu public est la plus simple et la plus répandue dans les traités canoniques et scolastiques.

\section{Vœu commun / vœu particulier}

6 Cette division provient de saint Augustin et est reprise par la glose biblique. Le vœu commun est celui que prononcent obligatoirement les membres de la communauté chrétienne. Ainsi, au moment du baptême, le baptisé fait vœu de renoncer à Satan et à toutes ses pompes. Le vœu particulier (votum proprium) est celui que le chrétien prononce en plus des vœux communs. L'exemple le plus courant est le vœu de continence. Chez saint Augustin le vœu commun est un concept fort. La communauté chrétienne de même que la cité antique se fonde sur le pacte constitutif de ses membres. Cet écho politique de la pensée augustinienne n'est pas vraiment perçu par les médiévaux, qui plaquent l'opposition entre vœu commun et particulier sur celle existant entre préceptes et conseils évangéliques ${ }^{5}$.

\section{Vœu tacite}

7 Le concept de vœu tacite est le produit de l'influence de la grammaire sémantique et de la philosophie du langage sur les juristes et théologiens de l'époque. La formule du vœu est entendue dans un double sens : celui de la grammaire et celui de l'intention du locuteur. Ce concept peut s'appliquer lorsqu'il existe une discordance entre l'intention et la formule. Celui qui énonce le vœu est alors considéré avoir prononcé aussi des vœux tacites. Ainsi, si je fais vœu de devenir prêtre, je fais aussi vœu tacitement d'être sousdiacre puis diacre, car l'ordination dans les ordres mineurs doit précéder celle dans l'ordre majeur. Ensuite, le vœu tacite permet de résoudre les incohérences grammaticales. Si je fais vœu « d'avoir prêtre » j'aurais néanmoins énoncé tacitement un vœu d'un énoncé grammaticalement correct. Enfin, le concept permet de contourner les impossibilités matérielles d'exécution du vœu. Si je ne sais pas que la Corse est une île et que je fais vœu d'aller à Bastia à pied depuis Paris, il faut rétablir le vœu tacite : «Je fais vœu d'aller à Bastia à pied tant que cela est possible. » Le vœu tacite est donc un concept très souple et qui est appliqué constamment dans la casuistique; il applique la psychologie de l'intention au vœu.

\section{Vœu annexe}

8 Le vœu annexe est celui qui est rendu nécessaire par la possession d'un état particulier. Ainsi le prêtre doit être continent et l'ordination comporte dès lors un vœu annexe de 
chasteté. Le vœu annexe est différent du vœu commun. Si le vœu commun tient à l'institution de l'Église et, par conséquent, est invariable et perpétuel, le vœu annexe est propre au droit ecclésiastique d'une période et d'une région déterminée. Ainsi les juristes médiévaux notent que le vœu annexe de continence n'existe pas chez les Byzantins ou en Occident avant la réforme grégorienne. Pour comprendre la nécessité du vœu annexe dans le droit ecclésiastique, il faut se souvenir que la Règle de saint Benoît ne contient pas le mot de « vœu » : le novice se contente de promettre l'obéissance pour devenir profès. Le vœu annexe répond au silence des textes.

\section{Lieux de la discussion et éventail de la casuistique}

\section{Gratien}

Le Décret de Gratien, écrit vers 1140, constitue le premier recueil général de droit canonique du Moyen Âge latin ${ }^{6}$. Son titre exact, la Concorde des canons discordants, rend compte de la volonté de l'auteur de rassembler les textes canoniques en les opposant selon leur opinion. L'originalité du Décret est contenue dans les dicta, où le maître propose une conciliation ou un dépassement des oppositions. Du fait de cette méthode de composition, les textes se rapportant au vœu sont dispersés dans plusieurs passages du texte, mais le lieu le plus important est la Causa 17 questio 1. En tête de cette Causa, Gratien pose le casus suivant dans son dictum: un prêtre malade fait vœu de se faire moine et abandonne son bénéfice. Il se rétablit et refuse d'accomplir son vœu. À la suite de ce casus, la questio 1 rassemble différents textes sur le vœu?

\section{Liber Extra}

10 En 1230, Grégoire IX charge le dominicain Raymond de Pennafort de rassembler les recueils antérieurs de décrétales, les Compilationes Antiquae, en un livre unique qui sera officiellement promulgué en 1234, le Liber Extra. Le vœu est abordé dans le trentequatrième chapitre du troisième livre qui a pour titre : Du vœu et de la rédemption des vœu ${ }^{8}$ . Les décrétales rassemblées traitent essentiellement du vœu de croisé.

Pierre Lombard, Sentences

Les Sentences de l'évêque parisien Pierre Lombard, composées vers 1155-1158, deviennent rapidement le manuel officiel de théologie à la base de l'enseignement à l'université de Paris ${ }^{9}$. Les innombrables commentaires dont il est l'objet constituent un lieu de discussion important de la théologie médiévale ${ }^{10}$. Le vœu est traité rapidement au livre quatre au sein de l'exposé sur le sacrement du mariage. À la distinction 38 , aux premier et deuxième chapitres, il est traité de l'effet du vœu de chasteté sur le mariage.

\section{Commentaires sur la Bible}

13 L'un des grands travaux de la première scolastique est la rédaction d'un commentaire exégétique sur l'ensemble de la Bible : la Glose ordinaire. Les gloses sur l'Écriture sont un lieu important de discussion de problèmes très variés. Les réflexions sur le vœu se concentrent sur le verset du psalmiste, dont l'ampleur dépasse l'explication de texte: «Vouez et rendez au Seigneur ${ }^{11}$.» Cependant certains épisodes rapportés par l'Ancien Testament peuvent servir de point de départ pour de petits traités de théologie morale. 
C'est le cas particulièrement du vœu de Jephté (Jug. 11, 29-40) auquel Étienne Langton consacre une question et sur lequel un pseudo-Hugues de Saint-Victor écrit un petit traité.

\section{Le traitement du vœu chez Robert de Courson}

Robert de Courson († 1219) est l'un des principaux élèves de Pierre le Chantre ${ }^{12}$. Il importe ici par son triple rôle d'intellectuel rédacteur d'une somme de théologie, de grand prélat, de juge délégué et de légat du pape, et enfin de prédicateur. Il est l'illustration parfaite des intellectuels «organiques" issus de l'Université qui envahissent la hiérarchie ecclésiastique au début du XIII ${ }^{\mathrm{e}}$ siècle $^{13}$. Dans sa somme datée entre 1208 et 1213, Robert traite longuement $d u v œ u^{14}$. Il place cette matière dans son plan entre les chapitres traitant du sujet, fort débattu à l'époque, des prébendes et de la simonie et ceux traitant des péchés de langue. Pour Robert de Courson, le vœu se place à mi-chemin entre le monde du clerc et celui de la parole. Chaque chapitre rassemble plusieurs distinctions ordonnées autour d'un thème général. Comme c'est le cas pour les œuvres de cette période, la rigueur logique du développement est faible. Les thèmes des différents chapitres donnent un bon exemple du champ de la casuistique concernant le vœu. Le chapitre 21 concerne la définition du vœu, ainsi la huitième distinction résout la question suivante : «Qu'est-ce qui solennise le vœu et la solennité fait-elle partie de la substance du vœu? » Le chapitre suivant traite de deux sujets et tout d'abord du vœu conditionnel, dont la quatrième distinction donne un exemple, celui de deux socii qui prononcent l'énoncé suivant: «Je fais vœu d'entrer au cloître si tu y entres." Le deuxième sujet abordé est celui de la commutation et la dixième distinction propose un exemple intéressant : doit-on dispenser de son vœu de jeûne le samedi, le roi Louis VII. La réponse est affirmative car, le ventre vide, le roi est moins apte à administrer la justice. Le chapitre 23 tourne autour du vœu de continence des clercs et le suivant de celui des religieux. Ce dernier est abordé par deux biais: le vœu des personnes mariées et la question du transitus, c'est-à-dire de la possibilité de changer d'ordre. Le transitus est l'un des points où se révèle la rivalité entre les ordres et particulièrement entre les moines et les chanoines.

Ainsi la casuistique se répartit en trois grandes familles : tout d'abord des questions de logique grammaticale ; ensuite des problèmes de désaccord entre le vœu et la morale ou le bien commun où l'on pose les limites de la liberté individuelle dans la société médiévale; enfin une importante partie de la casuistique traite du vœu de continence.

\section{Vovete et reddite Domino vestro}

La formule du douzième verset du psaume 76 (75) : «Faites des vœux et accomplissez-les pour le Seigneur votre Dieu ", dans la Vulgate : Vovete et reddite domino Deo vestro revient comme un leitmotiv dans toute la littérature médiévale sur le vœu. Une rapide esquisse des évolutions de l'interprétation médiévale du verset permet de suivre les mutations des doctrines. Le nœud du problème se situe dans la valeur à accorder à la conjonction « et ». Doit-on entendre qu'il y a concomitance du vœu et de son accomplissement, comme un acte qui suivrait immédiatement la pensée de ce dernier. Alors le chrétien se trouverait dans ce que le langage actuel de l'Église nomme la conversion permanente. À cette première lecture - la plus immédiate - les médiévaux en ont souvent préféré une 
seconde. Ils ont paraphrasé le verset ainsi : « Rendez au Seigneur ce que vous avez voué » ${ }^{15}$. La conjonction « et » rend compte de la succession non immédiate dans le temps et du rapport d'obligation. La promesse prononcée lors du vœu doit être accomplie. Cette fatalité de l'obligation est illustrée par Jephté qui avait promis, si Dieu lui assurait la victoire, de sacrifier celui qui viendrait à sa rencontre lors de son retour. Une malencontreuse coïncidence voulut que ce fût sa fille unique, Jephté dut la tuer ${ }^{16}$. Le Moyen Âge se demanda comment interpréter moralement ce crime. Faut-il seulement rejeter l'acte ou contester aussi sa légitimité ? La seconde explication fut généralement préférée ${ }^{17}$. Cette réprobation du vœu de Jephté marque l'évolution de la pensée médiévale qui sépare, dans le langage, l'intention de la signification. Le vœu prononcé avec une mauvaise intention, même s'il est cohérent grammaticalement, ne peut pas lier. Comme le dit, sèchement, Pierre Lombard: «Les vœux des sots doivent être rompus ${ }^{18}$.» Ceci remet en cause une exégèse $d u$ verset $d u$ psaume qui insiste sur l'obligation de l'accomplissement du vœu ${ }^{19}$.

17 Tiraillés entre une philosophie du langage raffinée et la place centrale du vœu et de la promesse dans la constitution politique de leur société, les intellectuels médiévaux bâtissent une autre interprétation du verset. Vovete et reddite sont quasiment synonymes, vovete signifie la deliberatio, acte mental ou en tout cas individuel, et reddite la promissio, l'énonciation publique de sa deliberatio ${ }^{20}$. Ce doublet du vœu se combine avec un autre, celui de la promesse. Elle peut être soit privée, prononcée à voix haute seule ou devant quelques amis, soit publique, par le biais d'un acte écrit ou par la solennité de son énonciation. Les penseurs médiévaux passent donc facilement d'un système de deux à trois étages et peuvent multiplier les divisions au gré de leur agilité intellectuelle. Au-delà des variations doctrinales, l'essentiel est que le vœu ne constitue pas un acte unique mais une succession dans le temps, une histoire. Le changement radical consiste à déplacer le centre de gravité qui se situait entre l'énonciation de la formule du vœu et sa réalisation effective pour le placer entre l'intention et la profération ${ }^{21}$. Ce modèle qui combine psychologie de l'intention et goût de la solennité, fut développé par les décrétistes, et repris par la théologie morale ${ }^{22}$.

\section{Annulation et commutation des voeux}

L'annulation ou la commutation des vœux est un des points centraux de discorde entre les différents juristes ou théologiens. S'y jouent les rapports de pouvoir entre le chrétien et l'autorité, qu'elle soit diocésaine ou pontificale. La tendance chez les décrétistes est de réduire les possibilités d'annulation et de commutation si l'intention répond à quelques caractères. Tout d'abord l'intention doit être véritable et provenir d'un individu qui a la capacité de s'engager. Cela exclut les incapaces : fous, serfs, etc. De plus l'objet du vœu doit être licite, c'est-à-dire qu'il correspond à quelque chose de raisonnable pour Dieu. Ainsi on peut annuler le vœu de tuer quelqu'un, puisque le commandement divin interdit le meurtre. Les décrétistes refusent largement au magistère le droit d'annuler ou de commuer les vœux des fidèles. Cette tendance culmine avec Huguccio de Pise. Une exception est faite pour la règle dite du transitus qui permet de commuer n'importe quel vœu en un vœu plus rigoureux, comme faire vœu de passer dans un ordre plus ascétique que celui dans lequel on est profès. 


\section{Le vœu comme contrat}

19 L'édifice complexe des décrétistes fondé sur la psychologie de l'intention et qui supprime toute possibilité de commutations était peu pratique et peu utilisable par les praticiens du droit canon. Les décrétalistes après un long silence dogmatique, revinrent donc à une doctrine plus simple. À l'opposition entre vœu simple et solennel, ils préfèrent le couple provenant de l'exégèse biblique: vœu commun, vœu particulier. Les décrétalistes s'intéressèrent au deuxième type de vœux qu'ils réintégrèrent dans la théorie du contrat : le vœu est un contrat entre un homme et Dieu. Le contractant et la forme du contrat doivent répondre à certaines qualités pour assurer la validité de l'acte. Le vœu une fois contracté amène des obligations mais aussi des empêchements. Le vœu, contrat perpétuel, peut néanmoins faire l'objet d'une dispense ou être commué dans des circonstances bien particulières, comme la «raison d'État ${ }^{23}$. L'autorité ecclésiastique joue un double rôle. Elle assure à la fois la publicité et juge de la légalité du vœu, mais de l'autre côté elle peut prendre un instant la place d'un des contractants, Dieu, pour mettre un terme ou transformer le contrat. La discussion va se porter sur ce deuxième rôle, quelque peu exorbitant. Dans quelles conditions, l'autorité ecclésiastique, et en particulier le pape, peut-elle dispenser ou commuer un vœu? L'opinion d'Hostiensis, qui attribue de larges pouvoirs au pape, va devenir dominante ${ }^{24}$.

Ce changement semble beaucoup plus visible dans le droit canon que dans la théologie morale. Les discours, auparavant largement communs, se séparent.

\section{NOTES}

1. Il faut ainsi rapprocher les discussions sur le vœu de celles sur le serment: Paolo Prodi, Il sacramento del potere, Il giuramento politico nelle storia costituzionale dell'Occidente, Bologne, Il Mulino, 1992.

2. Sur la grammaire sémantique, l'ouvrage de Sten Ebbesen éd., Sprachtheorien im Spätantike und Mittelalter, Tübingen, Gunter Narr Verlag, 1995, fournit une mise au point et une bibliographie à jour ; Irène Rosier, La parole comme acte. Sur la grammaire et la sémantique au XIII siècle, Paris, Vrin, 1994.

3. La bibliographie récente sur le vœu ne concerne que le droit: James A. Brundage, Medieval Canon Law and the Crusader, Madison/Londres, University of Wisconsin Press, 1969, deuxième chapitre (le traitement $\mathrm{du}$ vœu chez les décrétistes) et troisième (le vœu de croisé chez les décrétalistes). Pour le vœu en droit romain: Juliette Turlan, "L'obligation ex voto", Revue historique de droit français et étranger, 33, 1955, p. 502-536; Catherine Capelle. Le vœu d'obéissance des origines au XII ${ }^{e}$ siècle, thèse de droit, Paris, Librairie générale de droit et de jurisprudence, 1959. De nombreuses gloses intéressant notre sujet sont éditées dans Filippo Liotta, La continenza dei chierici nel pensiero canonistico classico da Graziano a Gregorio IX, Milan, Giuffré, 1971.

4. Sur le rite de la prise de croix : Brundage, op. cit., p. 118-120, et Kenneth Pennington, « The Rite for Taking the Cross in the Twelfth Century ", Traditio, 30, 1974, p. 429-435. 
5. Augustin dans les Enarrationes in Psalmos propose une exégèse du verset Vovete et Reddite (éd. CCSL, 33, p. 1048-1050) qui développe cette distinction. Selon lui, les vœux communs sont ceux que prête la communauté, un pacte chrétien qui répond au pacte social créateur de la cité. Cette subtilité ne se transmet pas dans la glose ordinaire de la Bible, qui ne reprend que la distinction entre vœux communs et vœux particuliers. Glossa ordinaria, ad Ps. 76 (75). 12 : Alia sunt comunia vota de his sine quibus nos est salvus, alia propria, ut vovere castitatem et huiusmodi. Aug(ustini). Parmi les exemples de vœux particuliers par Augustin, la glose ordinaire n'en a retenu qu'un seul : le vœu de chasteté.

6. Le Décret de Gratien est édité dans Emil Friedberg éd., Corpus Iuris Canonici, Leipzig, Tauchnitz, 1879 [= reprint Graz: Akademische Druck, 1959], t. I. Une présentation de cette œuvre de composition complexe dans : Jean Gaudemet, Les sources du droit canonique, VIII ${ }^{e}-X X^{e}$ siècle, Paris, Cerf, 1993, p. 103-119.

7. D'autres textes sur le vœu sont dispersés dans les D. 28 et D. 30, 31, qui traitent du clerc et de sa continence.

8. X 3.34 : De voto et voti redemptione. Pour l'édition du Liber Extra: supra, note 6.

9. Petrus Lombardus, Sententie in IV libris distincte, Grottaferrata, Collegium S. Bonaventurae, 1971-1981.

10. Artur Michael Landgraf, Introduction à l'histoire de la littérature théologique de la scolastique naissante, Paris, Vrin, 1973, p. 131-132.

11. Ps. 76 (75), 12 : Vovete et reddite Domino vestro.

12. Pour une présentation de Pierre le Chantre et de son « cercle» $: \mathrm{J}$. W. Baldwin, Masters, Princes and Merchants. The Social Views of Peter the Chanter and his Circle, Princeton, Princeton University Press, 1970. Sur la carrière de Robert de Courson article très documenté de Marcel et Christiane Dickson, «Le cardinal Robert de Courson: sa vie ", Archives d'histoire doctrinale et littéraire du Moyen Âge, 9, 1934, p. 53-142.

13. Pour utiliser le schéma de Gramsci repris par Jacques Le Goff, Les Intellectuels au Moyen Âge, Paris, Seuil, $1985^{2}$, p. III.

14. La table des matières de la somme a été éditée par Vincent L. Kennedy, «The Content of Courson's Summa », Medieval Studies, 9, 1947, p. 81-107.

15. C'est ainsi que l'entend l'Ecclésiaste : multoque melius est non vovere quam post votum promissa non complere (Eccl. 5, 3-4). La Summa 'Elegantius in iure divino' seu Coloniensis 4.81 paraphrase le verset ainsi : Idest si vovetis reddite, Gérard Fransen et Stephan Kuttner éd., t. 2, Cité du Vatican, 1978, p. 40.

16. Jug. 11, 29-40.

17. Voir par exemple Thomas, Summa 2a 2ae, q. 88 a. 2, ad 2, Thomas termine en disant Vota cero que sunt de rebus vanis et inutilibus sunt magis deridenda quam servanda. Robertus Cursonis, Summa 4.7, Paris, BN, lat. 3258, fo 114 qui indique, d'après un certain Iosephus (une interpolation à Flavius-Josèphe), que les intentions de Jephté n'étaient pas pures puisqu'il cherchait en fait un motif pour se débarrasser de sa femme.

18. Petrus Lombardus, IV Sent., D. 38 c. 1.

19. Ce discours se retrouve dans les statuts synodaux de Toul du XIV e siècle. Synod. Toul, 1359, c. 59 : Licet uniuscuiusque liberum fit arbitrium in vovendo, usque adeo tamen est necessaria solutio post votum in casibus in quibus votum emitti potest et debet, ut in ieiuniis, orationibus, eleemosynis, peregrinationibus, religionibus, abstinentiis, continentiis, et omnibus aliis piis causis licitis et honestis emissum ut sine salutis dispendio non liceat alicui auctoritate propria resilire, clamante propheta: "Vovete et reddite domino Deo vestro"(Ps. 76 (75).12). Idcirco ne circa voventes per indiscretos presbyteros incaute, sicut plerunque repertum est, contra voti remissionem vel gravitatem aut redemptionem aliquid agatur, prohibemus omnibus et singulis presbyteris in nostris civitate et diocesi constitutis ne super votis se aliquatenus intromittant, sed tales voventes, cum casus se obtulerit, ad nos aut nostros penitentiarios remittere non omittant, Baluze éd., Histoire généalogique de la maison d'Auvergne, 
Paris, 1708 , t. 2, p. 859-860. C'est une constante de la législation synodale de retirer au curé la compétence sur les vœux des laïcs au profit de l'évêque ou de l'un de ses subordonnés: archidiacre, official, ou ici pénitencier qu'il faut comprendre comme celui à qui l'évêque a délégué les questions de for interne, comme les cas réservés.

20. Cette idée d'une double étape dans le vœu du for interne à celui externe est contenue dans l'influente définition Petrus Lombardus, IV Sent., D. 38 c. 1: Votum est testificatio quedam promissionis spontanee, que Deo et de his que Dei sunt proprie fieri debet.

21. Ceci est exemplaire dans la glose interlinéaire ordinaire du verset du psalmiste. Glossa ordinaria, ad Ps. 76 (75),12 : Vovete : mente, quodlibet bonum et reddite : necessario post votum.

22. Ainsi Jean de Faenza distingue, la deliberatio - la considération d'un vœu possible -, le desiderium - la formulation de ce vœu - puis le vœu lui-même. Sicard de Crémone reprend ce schéma en distinguant dans la dernière étape le vœu, le vœu simple et solennel. Les décrétistes de la fin du $\mathrm{XII}^{\mathrm{e}}$ siècle rejettent l'idée que seul le vœu public lie, au contraire il suffit que l'intention soit suffisamment manifeste pour que le vœu devienne une obligation, Brundage, op. cit., p. 50-53. On voit bien ici l'influence de la morale de l'intention sur ce problème comme sur bien d'autres, à la fin du XII ${ }^{\mathrm{e}}$ siècle.

23. Hostiensis dans sa Summa Aurea 3.34.13 pose le casus suivant : Le roi des Sarrasins accepte de se convertir avec tout son pays, si on lui donne en mariage une certaine moniale. Selon lui, le pape peut alors dispenser du vœu de chasteté de la moniale car c'est une magna causa. Gérard d'Abeville traite du même casus dans un de ses quodlibets avec une solution identique, Brundage, op. cit., p. 105-106. Thomas reprend aussi l'argument du «bien commun » motif de la rupture du vœu de continence mais pour finalement s'opposer à toute possibilité de commutation, Summa 2-2ae, q. 88, a.11. On trouve auparavant des questiones des canonistes et des théologiens sur le casus du roi d'Aragon, Ramiro II le moine (1134-7) que l'on fit sortir de son monastère pour l'installer sur le trône le temps qu'il engendre un héritier, par exemple Robertus Cursonis, Summa, 24.6: Quod de concessione domini Pape claustrales sepe traditi sunt propter defectum heredis post sollempne votum? Item de facto et concessione Sedis Apostolice, iam tonsorati et professi monachi vel monache nobiles extracti sunt sepe a claustro et traditi matrimoni propter defectum heredum in regnis, ne periret res publica in ecclesia. Sed constat quod tales post votum sollempne contrahentes non fuerunt iuncti in legitimo matrimonio ergo non fuerunt in statu salvatorum ergo videtur quod ecclesia deceperit eos cum concessit eis contrahere sic post votum sollempne, Paris, BN, lat. $3258, \mathrm{f}^{\circ} .122 \mathrm{v}-123 \mathrm{r}$ ). Robert de Courson démontre ensuite sa solution en s'appuyant sur le fait que le moine n'acquiert pas de caracter au cours de sa profession qu'il définit comme une institutio modernorum au contraire des sacrements institués par le Christ.

24. Sur la pensée d'Hostiensis sur le vœu qui clôt l'évolution doctrinale, Brundage, op.cit, p. 99-107.

\section{AUTEUR}

\section{CHARLES DE MIRAMON}

Max Planck Institut, Francfort 